\title{
Synthesis and Characterization of Linear Poly (divinylbenzene- co-ethylvinylbenzene) Via A Cationic Solid Catalyst
}

\author{
N. BENSAADA, R. MEGHABAR and M. BELBACHIR \\ Departement of Chimistry, Laboratory of Polymer Chemical, Faculty of Science, \\ University of Oran, Es Senia BP 1524 El Menaouar, 31000 Oran, Algeria.
}

http://dx.doi.org/10.13005/ojc/290449

(Received: September 10, 2013; Accepted: October 27, 2013)

\begin{abstract}
The polymerization of divinylbenzene (DVB) catalyzed by Maghnite- $\mathrm{H}^{+}$is investigated. This paper shows that the cationic polymerization of DVB is initiated by Maghnite- $\mathrm{H}^{+}$at $28^{\circ} \mathrm{C}$ in bulk and gives the linear poly (divinylbenzene-co-ethylvinylbenzene) which is proved with ${ }^{1} \mathrm{H}$ and ${ }^{13} \mathrm{C}$ NMR spectra. The effect of the amount of Maghnite- $\mathrm{H}^{+}$on the molecular weight and the intrinsic viscosities is studied. The results indicate that the molecular weight and the intrinsic viscosities increased with the decrease in the proportion of catalyst. According to our results, a mechanism of this polymerization was proposed.
\end{abstract}

Key words: catalysts; Maghnite- $\mathrm{H}^{+}$; Cationic polymerization;

Divinylbenzene; poly (divinylbenzene-co-ethylvinylbenzene).

\section{INTRODUCTION}

The commonly used commercial divinylbenzene (technical grade) contains metaand para- isomers of divinylbenzene (DVB) and ethylvinylbenzene (EVB). It is usually composed of 50 to $80 \mathrm{wt} \% \mathrm{DVB}$, and, depending on polymerization methods, either linear or crosslinked polymers or copolymers of DVB can be prepared ${ }^{1}$.

The most popular method for preparing linear polydivinylbenzene is by using anionic polymerization techniques. With this method Aso et al obtain, in 1968, ortho-divinylbenzene using organolithium and alkali metal-naphtalene catalysts in various ethers ${ }^{2}$. Further work on this method was carried out by Bates et $\mathrm{al}^{3}$. They were able to produce homogeneous gels of DVB-EVB using technical grade DVB (60\% DVB, 40\%EVB), and either $n$-butyl lithium or sec-butyl lithium. In 1978, Nitadori and Tsuruta polymerized meta-divinylbenzene, as well as para-divinylbenzene, using lithium diisopropylamide (LDA) or butyl lithium as initiators ${ }^{4}$. However, a mixture of these same compounds (meta: para, 70:30) were synthesized by Hasegawa et al using $\mathrm{BF}_{3}-\mathrm{OEt}_{2}$ (oxoacids) as catalytic initiators, and 1, 2-dichloroethane as solvent ${ }^{5}$.

Acid-treated clays, such as montmorillonite, kaolinite, are widely used in a number of industrial significant reactions because they constitute an available, inexpensive solid source of protons. They 
have been employed as cracking catalysts until the $1960 s^{6}$, and are still used in industrial processes, such as alkylation of phenols ${ }^{7}$ and dimerization ${ }^{8}$ and polymerization of vinylic and heterocyclic monomers ${ }^{9-15}$. With their both Brønsted and Lewis acid sites, montmorillonites exchange cations having a high charge density with protons, producing highly active catalysts for acid-catalyzed reactions of polymerization ${ }^{7-10}$.

The main goal of this paper is to synthesize and characterize linear poly (divinylbenzene-coethylvinylbenzene) obtained from commercial divinylbenzene via Maghnite- $\mathrm{H}^{+}$, a new nontoxic cationic catalyst ${ }^{10}$. In this work, the characterization of the synthesized product was carried out by means of ${ }^{1} \mathrm{H}$ and ${ }^{13} \mathrm{C}$ NMR. The effect of the amount of the Maghnite- $\mathrm{H}^{+}$on both the molecular weight and the intrinsic viscosities of the product as well as the mechanism of initiation of this polymerization are discussed.

\section{EXPERIMENTAL}

\section{Materials}

The monomer [technical grade: $65 \%$ meta- and para-isomers of DVB, 33\% EVB and $2 \%$ of stabilizing (tert-butyl-4-pyrocatechol) Fluka], was purified by fractional distillation under reduced pressure. Methanol was initially dried over magnesium sulfate, and then distilled. Dichloromethane, (Aldrich Chemical) was used as received.

\section{Preparation of Maghnite- $\mathrm{H}^{+}$}

The preparation of the Maghnite- $\mathrm{H}^{+}$was carried out using a method similar to that described by Belbachir and al. ${ }^{10}$. The raw-Maghnite $(20 \mathrm{~g})$ was crushed for 20 min using a Prolabo ceramic balls grinder and dried by baking at $105^{\circ} \mathrm{C}$ for $2 \mathrm{~h}$. It was subsequently weighed and placed in an erlenmeyer flask together with $500 \mathrm{~mL}$ of distilled water. The suspension solution was first stirred using a magnetic stirrer and then combined, at room temperature, with $0.25 \mathrm{M}$ sulfuric acid, until saturation, which is achieved after 2 days. The product was washed with distilled water and finally dried at $105^{\circ} \mathrm{C}$ for $24 \mathrm{~h}$.

\section{Polymerization procedures}

DVB-EVB copolymers were obtained by using $7.69 \mathrm{mmol}(1 \mathrm{~g})$ of DVB and various amounts of Magnite- $\mathrm{H}^{+}(10,20,30$ and $50 \% \mathrm{wt})$. The mixtures were stirred with a magnetic stirrer under dry nitrogen. After $48 \mathrm{~h}$, the product was dissolved in 10 $\mathrm{ml}$ of dichloromethane. The catalysts were removed from the mixtures of the products by simple filtration. Subsequently, the filtrates were precipitated in 100 $\mathrm{ml}$ of methanol. The precipitates were then filtrated and dried in vacuum. The monomer conversion was determined gravimetrically by weighing the precipitated linear poly (DVB-co-EVB) chains.

\section{Characterization}

${ }^{1} \mathrm{H}$ and ${ }^{13} \mathrm{C}$ NMR spectra were recorded under ambient temperature on an AM 300 FT Bruker spectrometer using tetramethylsilane as internal standard and deuterated chloroform as solvent.

Gel permeation chromatography (GPC) measurements of the polymer were carried out using a WISP 712, Waters Associates chromatograph, THF was used as solvent and the instrument was calibrated to a first approximation with polystyrene of known molecular weight.

Intrinsic viscosity measurements were performed on SEMATECH Viscologic TI 1 apparatus at $25^{\circ} \mathrm{C}$ using THF as solvent.

\section{RESULTS AND DISCUSSION}

\section{Characterization of copolymer}

During the past, linear poly divinylbenzene by oxoacids initiating the cationic polymerization of DVB has been obtained ${ }^{5}$. In this paper, we try to use Maghnite- $\mathrm{H}^{+}$to initiate the polymerization of commercial DVB, and obtain a copolymer between EVB and DVB.

\section{Catalyst}

This study is concerned with cationic polymerization and examines the catalytic activity of a proton-exchanged montmorillonite clay called "Maghnite- $\mathrm{H}^{+}$" via DVB polymerization. The structure and the composition of the catalyst were reported in previous work ${ }^{10}$. The elementary analysis of Maghnite- $\mathrm{H}^{+}$, obtained using XRF spectroscopy and monomer conversions, show that there is an excellent correlation between the acid treatment and the catalytic activity of Maghnite- $\mathrm{H}^{+}$. Acid treatment of "raw-Maghnite" reduces the octahedral 
content $\left(\mathrm{Al}_{2} \mathrm{O}_{3}\right)$ which causes an increase in the proportion of silica $7,10,16,17$. It has been found that the best value for monomer conversion was obtained with raw-Maghnite treated by $0.25 \mathrm{M}$ sulfuric acid solution, in which there is a complete saturation of montmorillonite with protons without destruction of catalyst structure ${ }^{10}$.

\section{${ }^{1} \mathrm{H}$ and ${ }^{13} \mathrm{C}$ NMR measurements}

${ }^{1} \mathrm{H}$ and ${ }^{13} \mathrm{C}$ NMR spectra of polymer were recorded in $\mathrm{CDCl}_{3}$ using a Brucker AM $300 \mathrm{MHz}$ apparatus at $25^{\circ} \mathrm{C}$. These characterizations gave the following informations:

(1) The ${ }^{1} \mathrm{H}$ NMR spectrum (see figure 1) allowed confirmation of the structure of the copolymer obtained in this study. The signals between 6,9 and 7,4 ppm (h) are attributed to the aromatic protons; the signals observed between 5,25(f) and 5,8 ppm $(\mathrm{g})$ are attributed to the vinylic hydrogens (conjugation); the signals at 2,1 (c) and 2,4 (d) and 1,6 (b) ppm are assigned to methine, methylene and methyl protons of the polymer repeating unit respectively; the signals at 2,65 (e) and 1,25 ppm (a) are attributed to the $\mathrm{CH}_{2}$ and $\mathrm{CH}_{3}$ of the pendant ethyl groups from the EVB repeat unit (The letters used in the text are indicated on figures $1)$.

(2) The peaks of the ${ }^{13} \mathrm{C}-\mathrm{NMR}$ spectra are assigned as follows: the 128 ppm peak is attributed to phenyl $\mathrm{C}$; the $115 \mathrm{ppm}$ and 138 ppm are from $\mathrm{CH}=\mathrm{CH}$, the $28 \mathrm{ppm}$ peak is attributed to $\mathrm{CH}_{3}$. The resonances at $18 \mathrm{ppm}$ and 30 ppm are assigned to the $\mathrm{CH}_{3}$ and $\mathrm{CH}_{2}$ of the pendant ethyl groups from the EVB repeat unit and the $47 \mathrm{ppm}$ and $57 \mathrm{ppm}$ peaks are tentatively assigned to the $\mathrm{CH}_{2}$ and $\mathrm{CH}$ in the sequence of EVB units.

Table 1: Mn, I, and intrinsic viscosity of PDVB

\begin{tabular}{lccc}
\hline $\begin{array}{l}\text { Maghnite-H+/DVB } \\
\text { weight ratio (\%) }\end{array}$ & Mn $^{\mathrm{a}}$ & $\mathbf{I}^{\mathrm{b}}$ & $\begin{array}{c}\text { Intrinsic } \\
\text { viscosity }\end{array}[\mathrm{ml} / \mathrm{g}]$ \\
\hline 10 & 1369 & 1.75 & 3.59 \\
20 & 1324 & 2.13 & 3.12 \\
30 & 1215 & 2.00 & 2.68 \\
50 & 1178 & 2.09 & 1.97 \\
\hline
\end{tabular}

a determined by GPC with polystyrene standard; ${ }^{\mathrm{b}}$ I polydispersity index $(\mathrm{Mw} / \mathrm{Mn}) ;{ }^{\mathrm{c}}$ in $\mathrm{THF}$ at $25^{\circ} \mathrm{C}$.

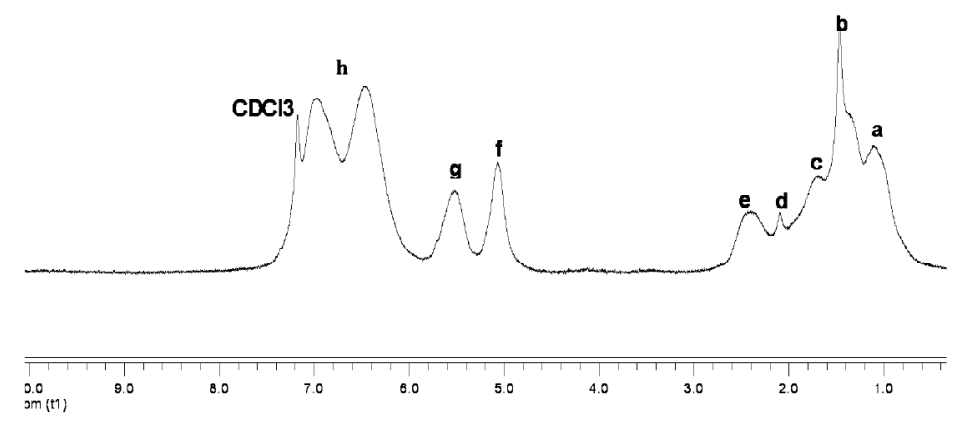

Fig.1: ${ }^{1} \mathrm{H}$ NMR spectrum of poly (divinylbenzene-co- ethylvinylbenzene) in $\mathrm{CDCl}_{3}$

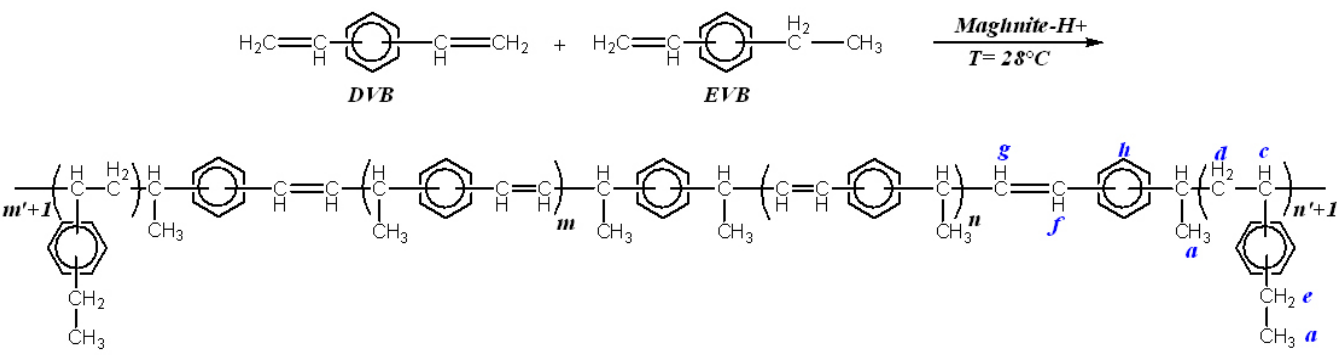

Scheme 1: Polymerization of DVB 
According to this analysis, the resulting poly (DVB-co-EVB) (PDVB) seems to be the only detectable product and no ambiguity remains on its structure.

\section{GPC and intrinsic viscosity Analysis}

Table 1 shows that the molecular weight and the intrinsic viscosity of PDVB increase when the proportion of Maghnite- $\mathrm{H}^{+}$decrease, thus clearly showing the effect of Maghnite- $\mathrm{H}^{+}$as a catalyst. This phenomenon is probably the result of number of 'initiating active sites' responsible of inducing polymerization, a number that is prorata to the catalyst amount used in the reaction ${ }^{18}$.

\section{Mechanism}

It has been reported that the cationic polymerization of DVB can be initiated by oxoacids in solution ${ }^{5}$. Using this procedure, commercial DVB was examined in the presence of Maghnite- $\mathrm{H}^{+}$powder in bulk at $28^{\circ} \mathrm{C}$.

The reaction between the components of commercial DVB leads to several products via cationic catalyst because of the presence of metaand para-isomers. It was found that the para-isomer polymerized more readily than the meta-isomer 1. The overall order of reactivity was: para-DVB > meta-DVB > meta-EVB > para-EVB ${ }^{19}$. Due to the relatively higher reactivity of para- and meta-DVB ${ }^{3}$,the proportion of DVB to EVB groups in the polymer was greater than in the monomer mixtures.

According to these relative reactivities of monomers ${ }^{19}$ and the mechanism proposed by Hasegawa and Higashimura ${ }^{5}$, we propose the following mechanism, which leads to the corresponding linear poly (DVB-co-EVB) as shown in Scheme 1.

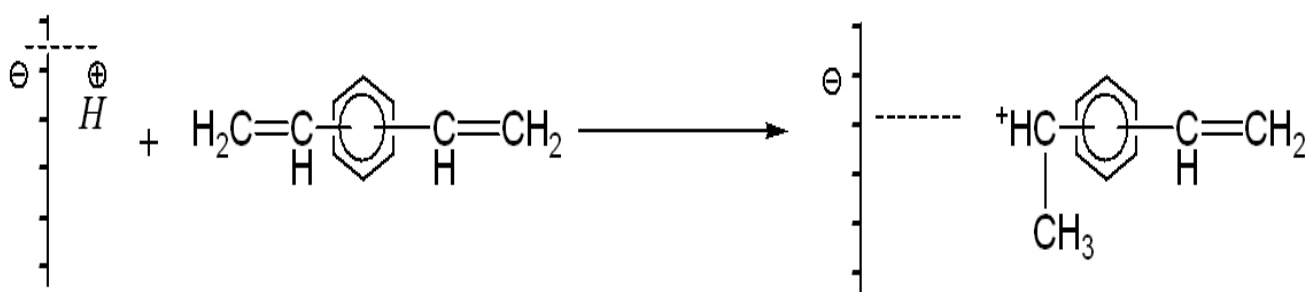

Scheme 2: Initiation
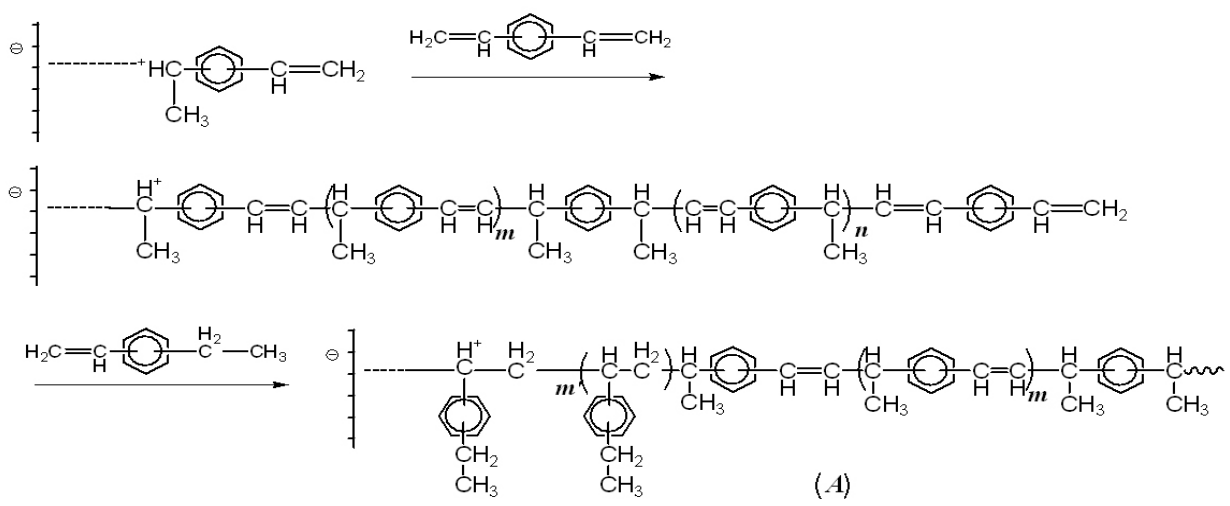

Scheme 3: Propagation

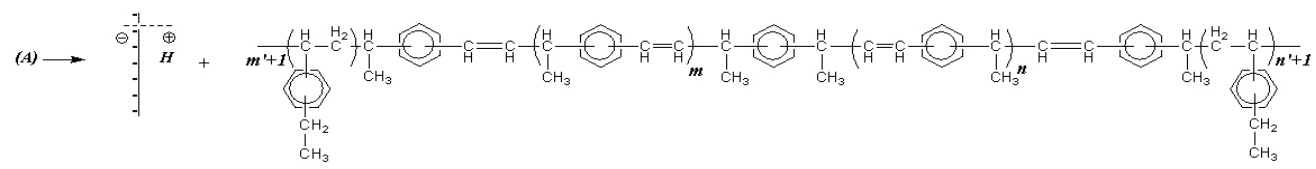


The polymerization of DVB is considered to be initiated between the initiator and a first molecule of DVB to form the active species (Scheme 2), the Maghnite- $\mathrm{H}^{+}$acting as counterion. Propagation is ensured by successive adjunction of DVB and is followed by successive adjunction of molecules of EVB (Scheme 3). Termination is probably caused by spontaneous transfer of EVB to the linear polymer growing chains (Scheme 4).

\section{CONCLUSION}

This paper provides a method for synthesizing linear copolymer of poly (divinylbenzene -coethylvinylbenzene) from commercial divinylbenzene via cationic catalyst. The linear polymerization was found to be initiated by Maghnite- $\mathrm{H}^{+}$powder. It has been shown that -the polymerization rate increased with the amount of Maghnite- $\mathrm{H}^{+}$, and the cationic catalyst role of Maghnite- $\mathrm{H}^{+}$for commercial DVB is clearly shown. Finally, the mechanism of polymerization was defined; the structure of the polymer explained and confirmed with ${ }^{1} \mathrm{H}$ and ${ }^{13} \mathrm{C}$ NMR spectra.

\section{ACKNOWLEDGEMENTS}

The authors would like to thank Dr. Ahmed Bensaada (Montreal) for helpful suggestions during the preparation of this paper.

\section{REFERENCES}

1. Hubbard KL, Finch JA, Darling GD. Reactive and functional polymers. 36: 1 (1998).

2. Aso C, Kunitake T, Imaizumi Y. Makromol Chemù. 116(14): 287 (1968).

3. Bates FS, Cohen RE. Makromolecules. 14: 881 (1981).

4. Nitadori Y, Tsuruta T. Macromol Chem. 179: 2069 (1987).

5. Hasegawa $\mathrm{H}$, Higashimura T. Makromolecules. 13: 1350 (1980).

6. Thomas CL, Hickey J, Stecker G. Ind Eng Chem. 42: 866 (1950).

7. Kaplan H. U.S. Pat. 3,287,422 (1966).

8. Hojabri F. J Appl Chem Biotechnol. 21: 87 (1971).

9. Ballantine JA, Davies $M$, Purnell $H$, Rayanakorn M, Thomas JM, Williams KJ. J Chem Soc Chem Commun. 427: 8 (1981).

10. Belbachir M, Bensaoula A. U.S. Pat. 6: 274,527 B1 (2001).

11. P.K. Reddy, K. Mukkanti and Dadda M. Rao, Orient J. Chem., 29(3): 1015-1019 (2013).
12. Meghabar R, Megherbi A, Belbachir, $M$. Polymer. 44: 4097 (2003).

13. Harrane A, Meghabar R, Belbachir M. Desig Monom and Polym. 8(1): 11 (2005).

14. Megherbi R, Belbachir M, Meghabar R. J Appl Polym Sci. 101: 78 (2006).

15. Harrane A, Meghabar R, Belbachir M. Reactive \& Functional Polymers. 66: 1696 (2006).

16. Ayat M, Harrane A, Belbachir M. J Appl Polym Sci.109: 1476 (2008).

17. Breen C, Madejova' J, Komadel P. J Mater Chem. 5: 469 (1995)

18. Breen C, Zahoor FD, Madejova J, Komadel P. J Phys Chem B. 101: 5324 (1997).

19. R. Soleymani, N. Niakan, S. Tayeb and S. Hakimi, Orient J. Chem., 28(1): 687-701 (2012).

20. Ferrahi MI, Belbachir M. eXPRESS Polymer Letters. 1: 24 (2007).

21. Walczynski B, Kolarz BN and Galina H. Polym Commun, 26: 276 (1985). 